\title{
Postprandial changes in portal haemodynamics in patients with cirrhosis
}

\author{
S O'Brien, M Keogan, S Patchett, P A McCormick, N Afdhal, J E Hegarty
}

\begin{abstract}
Previous studies have shown that portal venous pressure increases in patients with cirrhosis after a protein meal. Since this increase may be mediated by an increase in hepatic blood flow or postsinusoidal hepatic vascular resistance, the present study was designed to examine the precise relation between the postprandial changes in these three variables in patients with cirrhosis and portal hypertension. Estimated hepatic blood flow (EHBF; indocyanine green clearance), portosystemic gradient (PSG; wedged free hepatic venous pressure), and postsinusoidal hepatic vascular resistance (PSR $=$ PSG) EHBF) were measured simultaneously before and at $\mathbf{1 0}$ minute intervals after a high protein meal, containing $80 \mathrm{~g}$ protein, $40 \mathrm{~g}$ carbohydrate and $12 \mathrm{~g}$ fat $(600 \mathrm{kcal})$ in nine patients (seven alcoholic, two non-alcoholic) with cirrhosis and portal hypertension. After the meal, the portosystemic gradient increased by $33 \%$ from mean (SEM) $15.6(0.9) \mathrm{mm} \mathrm{Hg}$ to 20.7 $(1.3) \mathrm{mm} \mathrm{Hg},(p<0.01$; Wilcoxon signed ranks test) within 30 minutes. Coincident with this increase in portosystemic gradient, estimated hepatic blood flow increased by $69.2 \%$ from $20.1(1.7) \mathrm{ml} / \mathrm{min} / \mathrm{kg}$ to $33.9(2.5) \mathrm{ml} / \mathrm{min} / \mathrm{kg}$ $(p=0.01)$, peak values occurring at 25 minutes, at which time the postsinusoidal hepatic vascular resistance had decreased by $31 \%$ from $1.10(0.1) 10^{-2} \mathrm{~mm} \mathrm{Hg} / \mathrm{ml} / \mathrm{min}$ to $0.8(0.5)$ $10^{-2} \mathrm{~mm} \mathrm{Hg} / \mathrm{ml} / \mathrm{min}(p=0.01)$. These results suggest that the postprandial increase in portal venous pressure in patients with cirrhosis is mediated by an increase in hepatic blood flow and modified by a simultaneous decrease in postsinusoidal resistance.
\end{abstract}

Previous studies have shown that in patients with cirrhosis and portal hypertension, fasting portal venous blood flow is increased as a result of decreased splanchnic precapillary resistance, mediated by a variety of metabolic, neural, and humoral mechanisms. ${ }^{12}$ This increase in portal venous blood flow is associated with an increase in intrahepatic vascular resistance resulting from lobular architectural disruption, and is a major factor determining the increase in portal venous pressure observed in these patients. ${ }^{3-5}$ Several studies in humans have shown an increase in portal venous pressure after a meal, an effect which is more noticeable in patients with cirrhosis and portal hypertension. ${ }^{6-9}$ This exaggerated postprandial increase in portal venous pressure in cirrhotic patients may result from either a meal stimulated increase in splanchnic and hence portal venous blood flow, an increase in intrahepatic vascular resistance, or a combination of these effects. The present study was designed to examine the effects of a high protein meal on portal venous pressure and hepatic blood flow in patients with cirrhosis and portal hypertension and to define the temporal relation between the postprandial changes in portal pressure, hepatic blood flow, and hepatic vascular resistance.

\section{Methods}

PATIENTS

Nine patients (six men and three women), mean age 56 years (range 40-72 years) with compensated cirrhosis were studied. Seven patients had alcohol related liver disease, one patient had haemochromatosis, and one patient biliary cirrhosis. All patients had portal hypertension diagnosed on the basis of endoscopically shown oesophageal varices or splenomegaly, or both Relevant clinical data are summarised in Table I. Informed consent was obtained from each subject. Approval for the study was obtained from the Medical Ethics Committee at St Vincent's Hospital.

\section{PROCEDURES}

All patients were studied in the supine position after an overnight fast.

Measurement of portosystemic gradient

Portal pressure was measured as detailed previously. ${ }^{10}$ A $7 F G$ torque controlled balloon catheter (Cordis, USA), inserted into the right femoral vein using a Seldinger technique, was advanced to a main hepatic vein and the position

TABLE I Clinical details of the patients

\begin{tabular}{|c|c|}
\hline $\begin{array}{l}\text { Patients (no) (sex) } \\
\text { Age mean (range) (yrs) } \\
\text { Aetiology }\end{array}$ & $\begin{array}{l}9(6 M, 3 F) \\
55 \cdot 9(40-72) \\
\text { Alcoholic cirrhosis }(n=7) \\
\text { Haemochromatosis }(n=1) \\
\text { Biliary cirrhosis }(n=1)\end{array}$ \\
\hline Varices grade & $\begin{array}{l}\text { III }(n=3) \\
\text { II }(n=4) \\
\text { I }(n=1) \\
\text { None }(n=1)\end{array}$ \\
\hline Child's grade & $\begin{array}{l}A(n=5) \\
B(n=2) \\
C(n=2)\end{array}$ \\
\hline
\end{tabular}




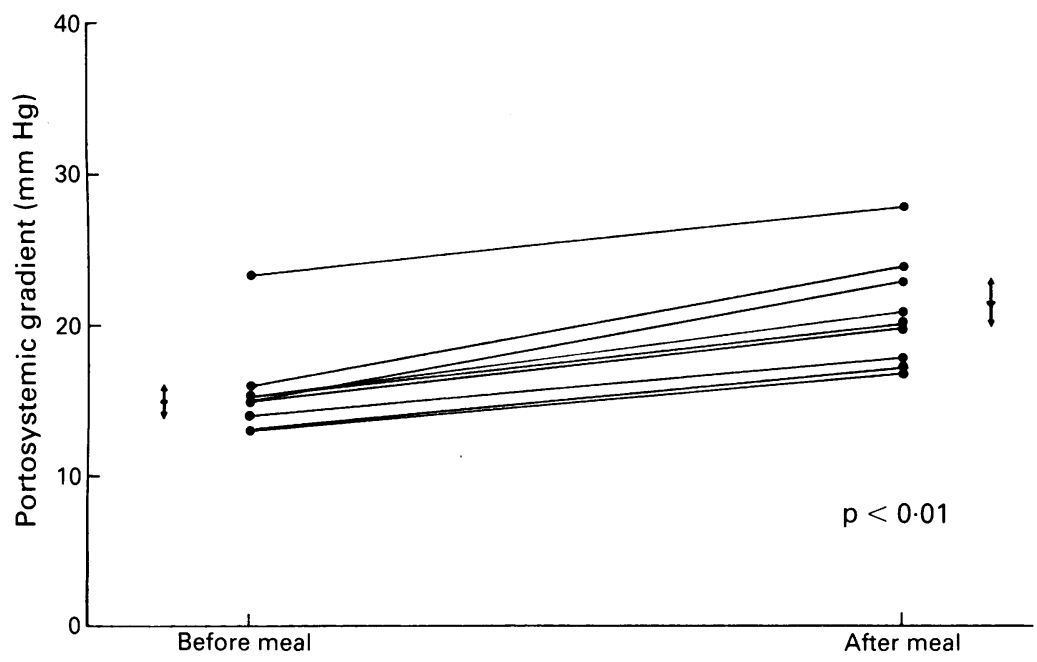

Figure 1: Postprandial changes in portosystemic gradient. Arrows indicate mean (SEM).

of the catheter tip checked in the free position using contrast medium. The balloon was inflated with $1.2 \mathrm{ml}$ of air and occlusion of the hepatic vein was confirmed after injection of contrast medium. A physiological pressure transducer (Gould Electronics) connected to a Horizon 2000 monitor was flushed with normal saline, calibrated using the free pressure at the level of the right atrium as a zero point, and attached to the balloon catheter. The portosystemic gradient was measured at five minute intervals for 20 minutes before the meal, and 10 minute intervals afterwards. On each occasion, the free and wedged hepatic pressures were measured twice and the mean portosystemic pressure gradient derived.

\section{Measurement of hepatic blood flow}

Hepatic blood flow was measured by indocyanine green (ICG) clearance using the continuous infusion method as detailed elsewhere"

Before the study the volume of distribution of ICG was determined. Five $\mathrm{mg}$ of ICG were injected rapidly, and serial blood specimens were collected in oxalated tubes and assayed within six hours by spectrophotometry. A semilog plot of

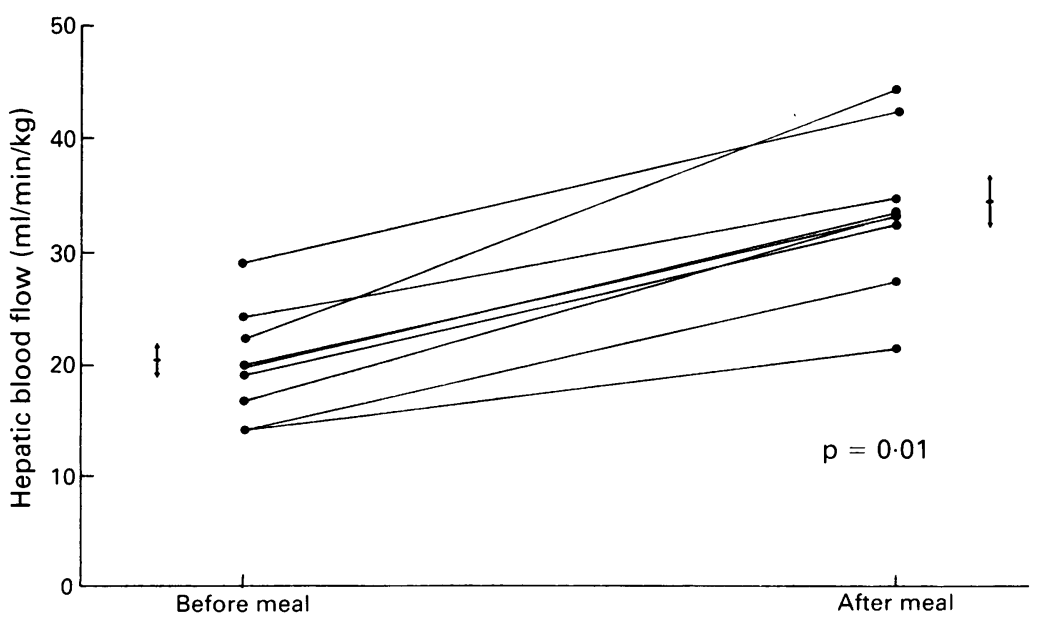

Figure 2: Postprandial changes in hepatic blood flow. Arrows indicate mean (SEM). decaying ICG values was constructed and interpolated to zero time to give the estimated instantaneous ICG value. The volume of distribution (Vd) was calculated from the formula:

$$
\mathrm{Vd}(\mathrm{ml})=\frac{\text { Dose }(\mu \mathrm{g})}{\text { Estimated instantaneous value }(\mu \mathrm{g} / \mathrm{ml})}
$$

Infusion of ICG was begun and an arterial line was inserted. After a bolus dose of $5 \mathrm{mg}$ ICG, infusion was begun at a rate of $0.5 \mathrm{mg} / \mathrm{min}$ and a minimum of 20 minutes was allowed for equilibration. Five simultaneous arterial and hepatic venous samples were drawn at five minute intervals before ingestion of the meal and at $15,25,35,45$, and 55 minutes after the meal. In addition arterial samples were drawn between paired samples to allow calculation of the rate of change of the arterial ICG value. The estimated hepatic blood flow (EHBF) was calculated from the formula:

$\operatorname{EHBF}(\mathrm{ml} / \mathrm{min})=\frac{\mathrm{RI}+/-(\mathrm{dc} / \mathrm{dt} \times \mathrm{Vd})}{\mathrm{Ca}-\mathrm{Chv}} \times \frac{100}{100-\mathrm{Hct}}$

Where: $\mathrm{RI}=$ rate of infusion of $\mathrm{ICG}$; $\mathrm{dc} / \mathrm{dt}=$ rate of change of arterial ICG; $\mathrm{Vd}=$ volume of distribution of ICG; $\mathrm{Ca}=$ arterial concentration of ICG; $\mathrm{Chv}=$ hepatic venous concentration of ICG; Hct = haematocrit.

The correction factor $\mathrm{dc} / \mathrm{dt}$ was included to account for the difference between the rate of elimination and the rate of infusion in the nonsteady state. The mean of the basal hepatic blood flow measurements was taken as the preprandial value. Hepatic extraction of ICG (Ca-Chv) was greater than $10 \%$ of estimated hepatic blood flow in all patients.

STUDY MEAL

A liquid meal containing $80 \mathrm{~g}$ of protein, $40 \mathrm{~g}$ carbohydrate, $12 \mathrm{~g}$ fat and $600 \mathrm{kcals}$ was given to each patient. It was prepared from $38 \mathrm{~g}$ Build-Up powder, $60 \mathrm{~g}$ Casilan, and $300 \mathrm{ml}$ milk made up to $500 \mathrm{ml}$ with water. The meal was consumed within 10 minutes.

CALCULATION OF POSTSINUSOIDAL RESISTANCE Postsinusoidal hepatic vascular resistance (PSR) was calculated using the formula":

$$
\text { PSR }=\frac{\text { Transhepatic pressure gradient }}{\text { Hepatic blood flow }}
$$

Transhepatic pressure gradient was calculated as wedged minus free hepatic venous pressure.

TABLE II Changes in free hepatic venous pressure (FHVP), wedged hepatic venous pressure (WHVP), and portosystemic

\begin{tabular}{|c|c|c|c|c|c|c|}
\hline \multirow[b]{2}{*}{ Patient no } & \multicolumn{2}{|c|}{$F H V P(m m H g)$} & \multicolumn{2}{|c|}{$W H V P(m m ~ H g)$} & \multicolumn{2}{|c|}{$P S G(m m H g)$} \\
\hline & Before & After & Before & After & Before & After \\
\hline 1 & 2 & 0 & 25 & 28 & 23 & 28 \\
\hline 2 & 5 & 5 & 20 & 21 & 15 & 16 \\
\hline 3 & 2 & 2 & 18 & 23 & 16 & 21 \\
\hline 4 & 4 & 2 & 18 & 20 & 14 & 18 \\
\hline 5 & 0 & 1 & 15 & 21 & 15 & 20 \\
\hline 6 & 4 & 5 & 17 & 22 & 13 & 17 \\
\hline 7 & i & -2 & 17 & 22 & 16 & 24 \\
\hline 8 & 5 & 4 & 20 & 24 & 15 & 20 \\
\hline 9 & 0 & 0 & 15 & 23 & 15 & 23 \\
\hline
\end{tabular}
gradient (PSG) before and after a meal 


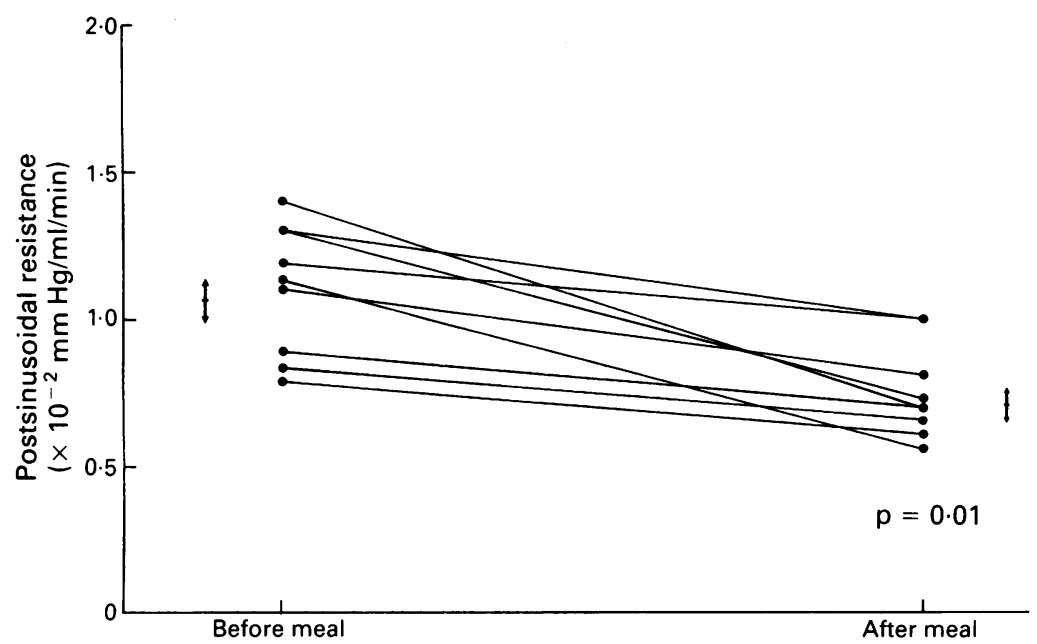

Figure 3: Postprandial changes in postsinusoidal resistance. Arrows indicate mean (SEM).

\section{ANALYSIS}

All data are reported as mean (SEM). Mean maximal values refer to the mean of the maximal values obtained in the individual patients. Pre and postprandial values were compared using a Wilcoxon signed ranks test.

\section{Results}

Within 30 minutes of the meal, the portosystemic gradient increased by $33 \%$ from a basal value of $15.6(0.9) \mathrm{mm} \mathrm{Hg}$ to a mean maximal value of $20.7(1.3) \mathrm{mm} \mathrm{Hg},(\mathrm{p}<0.01)$, (Fig 1). Estimated hepatic blood flow increased by $69 \cdot 2 \%$ from $20 \cdot 1$ $(1 \cdot 7) \mathrm{ml} / \mathrm{min} / \mathrm{kg}$ to $33.9(2.5) \mathrm{ml} / \mathrm{min} / \mathrm{kg}$, ( $\mathrm{p}=0.01$ ), (Fig 2). Postsinusoidal hepatic vascular resistance decreased by $31 \%$ from a basal value of $1 \cdot 1(0 \cdot 7) \mathrm{mm} \mathrm{Hg} / \mathrm{ml} / \mathrm{min}$ to a mean minimal value of $0.8(0.5) \mathrm{mm} \mathrm{Hg} / \mathrm{ml} / \mathrm{min}$, $(p=0.01)$, Fig 3). In all nine patients the trends observed with each variable were consistent as shown in Figures 1, 2, and 3. The time course of the postprandial changes in portal venous pressure parallelled that of the changes in hepatic blood flow with reciprocal changes in postsinusoidal hepatic vascular resistance. (Fig 4).

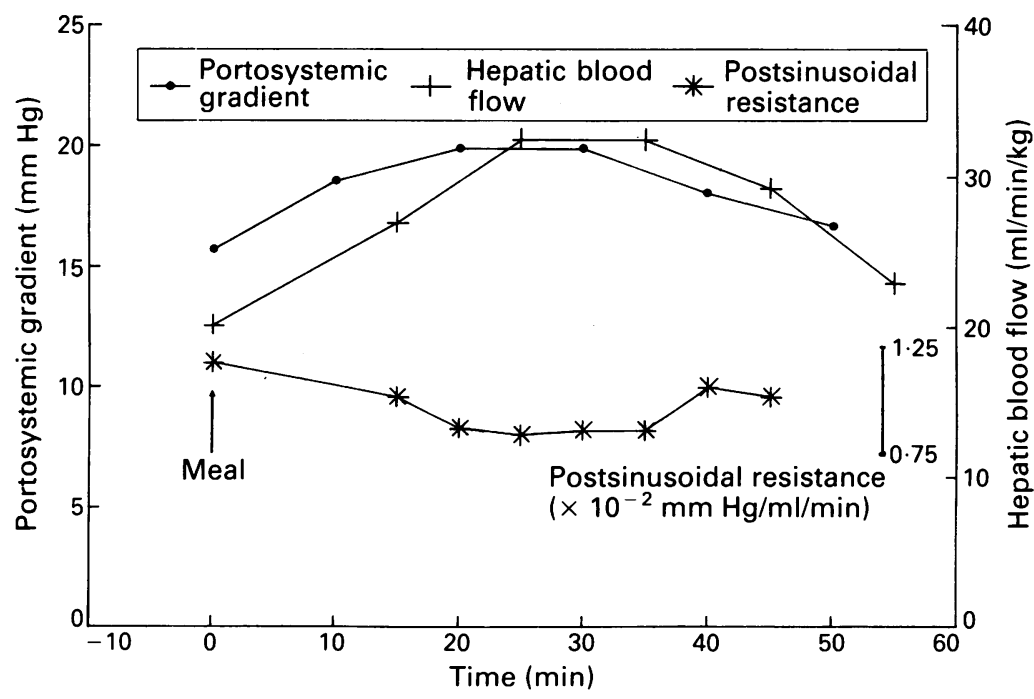

Figure 4: Temporal relation between the postprandial changes in portosystemic gradient, hepatic blood flow, and postsinusoidal resistance. Values at each timepoint represent the mean of values for the nine patients.

\section{Discussion}

The results of this study show that after a high protein meal the hepatic venous pressure gradient and total hepatic blood flow increased by $33 \%$ and $69 \%$ respectively and were associated with a $31 \%$ reduction in hepatic vascular resistance. This increase in total hepatic blood flow may have been related to an increase in hepatic arterial or portal venous flow since indocyanine green clearance cannot discriminate between changes in the individual components of total hepatic blood flow. Previous studies have shown that splanchnic, and hence portal, blood flow increases in the postprandial state and that under a variety of conditions there are reciprocal changes in hepatic arterial and portal venous blood flow. ${ }^{1214}$ Thus, the postprandial increase in total hepatic blood flow observed in this study is likely to be predominantly related to an increase in portal venous blood flow. Since pressure in any vascular system is determined by flow and resistance within that system, an increase in the postprandial portal blood flow would account for the increase in hepatic venous pressure gradient.

The results of the present study agree with those of Lee et al but conflict with those of Gaiani, who showed no increase in blood flow after a standard Italian meal. ${ }^{815}$ Estimates of portal venous blood flow in the latter study, however, were performed 60 minutes after the meal and it is possible that an increase in portal blood flow had occurred earlier as was shown in the present study and that of Lee et al. ${ }^{8}$

Of major physiological interest is whether or not pressure dependent autoregulation of blood flow is present within the hepatic vascular bed. ${ }^{12}$ The assessment of pressure dependent autoregulation of blood flow depends on the relation between the pressure gradient (portal venous hepatic venous pressure) and the calculated vascular resistance (pressure gradient/blood flow). In vascular beds that exhibit flow directed autoregulation, resistance increases with increasing pressure - tending to maintain blood flow constant. In vascular beds that exhibit pressure directed autoregulation, vascular resistance either remains constant or decreases with increasing pressure, and blood flow and perfusion pressure have a direct relation. ${ }^{12}$ The results of this study suggest that flow directed autoregulation does not occur to any great extent within the hepatic vascular bed since the increase in hepatic blood flow was associated with a decrease in hepatic vascular resistance, a situation which prevents extreme rises in portal pressure during periods of increased splanchnic/portal blood flow. The reduction in hepatic vascular resistance is a dynamic variable that can modify change in portal venous haemodynamics. ${ }^{16}$ It is possible that the meal related reduction in hepatic vascular resistance observed in this study results from an inhibition of sympathetic nervous system activity, as has been shown after administration of clonidine to patients with cirrhosis and portal hypertension, or to the release of vasoactive digestive products, metabolites, or gut hormones. ${ }^{1617}$ It should be emphasised, however, that any conclusions based on changes in hepatic vascular resistance - a derived variable should be treated with caution. 
Of particular interest is the possible role of glucagon in mediating the postprandial increase in portal venous blood flow. Several studies have shown that plasma glucagon concentrations rise in the postprandial state and that the size of the increase in these values is directly related to the protein content of the meal. ${ }^{18-20}$ Moreover, the increase in plasma glucagon values has been associated with increased organ blood flow. ${ }^{21} 22$ In addition, administration of supraphysiological doses of glucagon to patients with compensated cirrhosis has been shown to increase splanchnic blood flow as determined by increases in azygous blood flow. ${ }^{23}$

The pharmacological control of portal hypertension has attracted considerable attention over the last decade. Several vasoactive drugs including $\beta$ adrenoreceptor antagonists and venodilators have been shown to reduce portal venous blood flow and pressure, and based on their haemodynamic effects, their use has been advocated for the prevention of recurrent bleeding from oesophageal varices. ${ }^{2426}$ Controlled clinical trials evaluating the use of $\beta$ adrenoreceptor antagonists in the prevention of variceal haemorrhage have, however, yielded conflicting results and in one such study propranolol was shown to be of no benefit in the prevention of recurrent haemorrhage despite the observation that portal pressure was significantly reduced in the propranolol treated group. ${ }^{28}$ The effects of vasoactive drugs, including propranolol, on portal haemodynamics in patients with portal hypertension have been evaluated in the fasted state in most if not all studies and did not consider dynamic changes in portal blood flow - for example, after a meal - which may be mediated by mechanisms unaffected by $\beta$ receptor blockade. Assuming that the degree of portal venous pressure is an important factor determining the likelihood of bleeding or rebleeding from oesophageal varices, then the results of the present study would suggest that the evaluation of pharmacological agents considered for use in the management of portal hypertension should include an assessment of their effects on postprandial portal haemodynamics.

This paper 'Postprandial changes in portal haemodynamics in patients with cirrhosis' has been published in $G u t$ in abstract form O'Brien S, Keogan M, Afdhal N, Patchett S, and Hegarty JE. Postprandial changes in portal haemodynamics in patients with cirrhosis. Gut 1989; 30: A1498.

1 Benoit JN, Barrowman JA, Harpur SL, Kvietys PR, Granger ND. Role of humoral factors in the intestinal hyperaemia associated with chronic portal hypertension. Am $\mathcal{F}$ Physiol 1984; 247: G486-493.

2 Parks DA, Jacobson ED. Physiology of the splanchnic circulation. Arch Intern Med 1985; 145: 1278-81.

3 Benoit JN, Womac WA, Hernandez L, Granger ND. 'Foreward' and 'backward' flow mechanisms of portal hyper- tension. Relative contribution in the rat model of portal vein stenosis. Gastroenterology 1985; 89: 1092-6.

4 Sikuler E, Groszman R. Interaction of flow and resistance in maintenance of portal hypertension in a rat model. Am $\mathcal{F}$ Physiol 1986; 250: G205-12.

5 Lee SS, Hadengue A, Girod C, Braillon A, Lebrec D. Reduction of intrahepatic vascular space in the pathogenesis of portal hypertension. In vitro and in vivo studies in the rat. Gastroenterology 1987; 93: 157-61.

6 Castleman L, Brandt JL, Ruskin HD. The effect of oral feeding of meat and glucose on hepatic vein pressure in
normal and cirrhotic subjects. F LabClin Med 1958; 51;897.

7 Orrego H, Mena I, Barona E, Palma R. Modifications in hepatic blood flow and portal pressure produced by different diets. Am f Dig Dis 1965; 10: 239-48.

8 Lee SS, Hadengue A, Moreau R, Sayegh R, Hillon P, Lebrec D. Postprandial haemodynamic responses in patients with cirrhosis. Hepatology 1988; 8: 647-51.

9 Brandt JL, Castleman L, Ruskin HD, Greenwald J, Kelly JJ. The effect of oral protein and glucose feeding on splanchnic blood flow and oxygen utilization in normal and cirrhotic subjects. F Clin Invest 1955; 34: 1017-21.

10 Groszmann RJ, Glickman M, Blel AT, Storer E, Conn HO. Wedged and free hepatic venous pressure measured with a balloon catheter. Gastroenterology 1979; 76: 253-8.

11 Villeneuve JP, Huot R, Marleau D, Huet PM. The estimation of hepatic blood flow with indocyanine green: comparison between the continuous infusion and single injection between the continuous infusion and single

12 Richardson PDI, Witherington PG. Liver blood flow. Gastroenterology 1981; 81: 159-73.

13 Laut WW. Control of hepatic arterial blood flow: independance from liver metabolic activity. A $m$ f Phvsiol 1980; 239 H559-64.

14 Lautt WW. Relationship between hepatic blood flow and overall metabolism: the hepatic arterial buffer response. $F e d$ Proc 1983; 42: 1662-6.

15 Gaiani S, Bolondi L, Bassi S, Santi V, Zironi G, Barbara L. Effect of meal on portal haemodynamics in healthy humans and in patients with chronic liver disease. Hepatology 1989; 9: 815-9.

16 Willett IR, Jennings G, Esler M, Dudley FJ. Sympathetic tone modulates portal venous pressure in alcoholic cirrhosis. Lancet 1986; ii: $939-43$.

17 Siregar H, Chou CC. Relative contribution of fat, protein, carbohydrate and ethanol to intestinal hyperaemia. Am F Physiol 1982; 242: G27-31.

18 Ishida T, Chou J, Lewis RM, Hartley CJ, Entman M, Field $\mathrm{JB}$. The effect of ingestion of meat on hepatic extraction of insulin and glucagon and hepatic glucose output on conscious dogs. Metabolism 1983; 32: 558-66.

19 Muller WA, Faloona GR, Aguilar-Parada E, Unger RH Abnormal alpha-cell function in diabetes. $N$ Engl $7 \mathrm{Med}$ 1970; 283: 109-15.

20 Pek S, Fajans SS, Floyd JC, Knopf RF, Conn WJ. Effect upon plasma glucagon of infused and ingested amino acids and of protein meals in man. Diabetes 1969: 18: 328-32.

21 Premen AJ, Hall JE, Smith MJ. Postprandial regulation of renal haemodynamics: role of pancreatic glucagon. Am F Physiol 1985; 248: F656-62.

22 Silva $G$, Navasa $M$, Bosch J, et al. Haemodynamic effects of glucagon in portal hypertension. Hepatologv 1990; 11 668-73.

23 Lee SS, Moreau R, Hadengue A, Cerini R, Koshy A, Lebrec D. Glucagon selectively increases splanchnic blood flow in patients with well compensated cirrhosis. Hepatology 1988 8: $1501-5$.

24 Lebrec D, Poynard T, Hillon P, Benhamou JP. Propranolol for the prevention of recurrent gastrointestinal bleeding in patients with cirrhosis: a controlled study. $N$ Engl $\mathcal{F}$ Med patients with cirrh

25 Colombo M, DeFranchis R, Tommasini M, Sangiovanni A Dioguardi N. Beta-blockade prevents recurrent gastrointestinal bleeding in well-compensated patients with alcoholic cirrhosis: a multicentre randomised controlled trial. Hepatology 1989; 9: 433-8

26 Kong CW, Lay WS, Tsai YT, et al. The haemodynamic effect of verapamil on portal hypertension in patients with postnecrotic cirrhosis. Hepatologv 1986; 6: 423-6.

27 Villeneuve JP, Pomier-Layrargue $G$, Infante-Rivard $C$, Williams B, Huet PM, Marleau D, et al. Propranolol for the prevention of recurrent variceal haemorrhage a controlled trial. Hepatology 1986; 6: 1239-43.

28 Burroughs AK, Jenkins WJ, Sherlock S, et al. Controlled trial of propranolol for the prevention of recurrent variceal

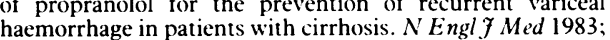
309: $1539-42$. 